\title{
The Use of Humour in the Off-task Spaces of the Language Classroom
}

\author{
Mabel Victoria
}

The focal point of most investigations into classroom discourse tends to be on the institutionally sanctioned and legitimized on-task exchanges between teachers and students with particular attention to the IRF/E structure. Liminal spaces of interaction such as during the small talk just before the 'lesson proper', transitions between activities, and playful moments before or immediately after breaks are often unexplored. Using transcribed naturalistic spoken data collected via participant observation over 12 weeks, examples of teacher-initiated humour are analysed to shed light on how off-task, 'non-teaching' spaces can be used as a pedagogical resource. This study puts the spotlight on how humour can be deployed in these obscured interstices of the L2 classroom to create a space not only to build rapport between students and teachers but also to impart new vocabulary and sociocultural knowledge.

\section{Introduction}

How can teachers make productive use of classroom time while waiting for a couple of stragglers to get settled in their seats? How can the few moments before coffee breaks, when students might be less attentive, be made into opportune learning and teaching moments? While classroom talk has been the subject of numerous studies, these investigations tend to concentrate on the 'lesson proper' where teachers and students engage in curriculum-orientated talk. The focus here, however, is on the neglected crevices that can be considered non-curriculum oriented or off-task and their potential as pedagogical resource.

This paper shows how a teacher at a Canadian educational context used humour to transform the unexplored, less legitimate spaces of the classroom into teaching moments. Iterative review of the entire corpus shows that there is a congruent relationship between the frequency of the use of humour and stages of the lessons. Funny stories, canned jokes, and teasing with accompanying laughter tend to be clustered in specific phases of the class - the few minutes at the start or the end of the lesson, transitions between activities, and just before or after coffee breaks. Data excerpts analysed in Section 3 suggest that these non-curriculum oriented spaces can be fertile sites for teaching vocabulary, grammar, functions and other important aspects of language use in a non-threatening, fun way.

\section{Humour in Teaching and Learning}

Humour has sometimes been conceptualised as 'verbalizations that elicit or are intended to elicit laughter' (Bell 2006:4). In order to take into consideration the subjective role of the researcher in the analysis, this paper also draws on Holmes's 
view of humour as 'utterances which are identified by the analyst, on the basis of paralinguistic, prosodic and discoursal clues, as intended by the speaker(s) to be amusing and perceived to be amusing by at least some participants' (Holmes 2000: 163).

The benefits of humour in the classroom have long been recognised by scholars. In addition to enhancing solidarity and relieving tension, humour is said to play a role in reinforcing students' memory of knowledge and retention of information (Garner 2006; White 2001); and clarifying course material (Downs, Javidi, \& Nussbaum 1988). In the L2 classroom, researchers have found that verbal humour which includes funny anecdotes, puns and wordplays contribute to the sociolinguistic and sociocultural competence of the learner (Bell2009; Ziyaeemehr, Kumar, \& Abdullah, 2011). While it would be an over ambitious claim to state that humour always leads to learning, I suggest that humour, alongside other social and contextual factors, can contribute to the creation of a positive and enjoyable environment in such a way that the 'ha-ha' facilitates the achievement of the 'aha' (Garner 2006:178).

\section{The Study}

The research site for this study was a college in Canada that runs ESL and job search programmes for adult newcomers to the country. The data reported here is part of a larger study that investigated the communication strategies used by NNS in English as lingua franca encounters. The language and job search programme consisted of 12 weeks of classroom instruction (six hours a day, five days week) and 20 weeks of onthe-job training. Classroom content included English for Employment, Interpersonal and Intercultural skills, Computer Training, First Aid, and Job Safety. There were seven participants, aged between 25 and 50, who had migrated to Canada from the Republic of the Congo, Haiti, Bangladesh, Jordan, the Philippines, and India (two students). Since they came from seven different linguistic backgrounds - Lingala, French, Bangla, Filipino, Hindi, Punjabi and Arabic - English served as the common language of communication. Their English ability was tested before they were admitted to the programme and it was deemed that their level was of a 'high enough intermediate level to be able to undertake academic and employment preparation courses.'

The three teachers who were involved in programme delivery-two males and one female, between the ages of 35 and 60-had lived all their lives in Canada. They all had at least three years of working with Canadian immigrants in educational and job search contexts. The extracts in this paper focus on the lead teacher, Tom (a pseudonym), because he taught the L2 module.

\section{Methods of Data Collection}

Participant observation and data collection took place over a period of 12 weeks from September to November 2009. This consisted of approximately150 hours of audio recordings of naturalistic classroom interaction and eight hours of semi-structured interviews. Given the aim of this paper to analyse teacher's use of humour in off-task spaces, the interview data is not included in the analysis. Only spoken interactions were recorded, so the transcriptions do not reflect times when the students were writing, reading, working at their computer or on field trips. To record interactions, two unobtrusive digital recorders were used; one placed on the teacher's desk and the other close to the researcher. 
I listened iteratively on Express Scribe to the 150 hours verbal data compiled and made rough transcriptions on the system. I 'bookmarked' salient data using the software and based on the data-derived code, I decided to transcribe around 32 hours in detail, with transcription conventions. Approximately 650 minutes each from September, October and November were transcribed. The level of transcription detail (see Appendix for transcription conventions) used was fine-grained so as to capture paralinguistic features (pauses, gestures, hesitation markers), prosody (stress, loudness) and discourse textures (overlapping speech, latching). Admittedly, audio recording cannot capture the full complexity of the interaction despite my best attempts to include non-verbal features and gestures in my field notes. Video recording was initially considered but it was felt that it would be too distracting for the teachers and students. Since the analysis was not intended to be multi-modal, audio recording with participant observation was deemed the most suitable data collection method. However, despite any drawbacks with the methods used, being physically present in the room enabled me to make notes on as much non-verbal information as possible.

\section{Data and Data Analysis}

I used Express Scribe software to transcribe the recordings in detail. The software has a special feature which enabled me to 'bookmark' sections of interest. Upon iterative listening and checking my field notes against the bookmarked sections, it became noticeable that the instances of laughter clustered around the off-task spaces, mostly around peripheries of the lesson proper and around coffee breaks. It seemed that the teacher deployed humour strategically by demarcating phases of the lesson as being serious or non-serious. In doing so, the hearable message from the students' perspective is perhaps something like 'all work and no play makes Jack a dull boy.' The data suggest that most playful interactions were introduced by the teacher. This is unsurprising considering the asymmetrical nature of the institutional talk. Given the space limitations, I focus the analysis on the teacher-initiated humour, which is not to say that students did not instigate humorous exchanges. Since the perspective privileged in the analysis is that of the teacher's, there is a caveat that students' smiles and laughter at opportune moments necessarily indicate amusement or understanding of the humorous intent. Indeed, students might laugh to feign understanding and save face or simply because the teacher or the other students were laughing. The data excerpts below present naturally occurring data of humour introduced by Tom , the teacher, during off-task moments: first thing in the morning while setting up the audio-visual equipment and waiting for the rest of the class to arrive, after lunch while getting ready for a field trip, just before coffee break after an intensive morning and during transition moments between a lecture and a writing activity.

\section{Extract 1 Trick or Treat}

A few days before Halloween, Tom, walks into the classroom with a few minutes to spare before class. There were only three students present. While waiting for the rest of the class to arrive and getting the audio-visual equipment ready, he engages one of the students, Faisal, in a conversation.

394 Tom TRICK or TREAT! You know what that means (.) Faisal? TRICK or TREAT?

395 Faisal NO, erm, n::o! (shakes his head)

396 Tom You know what that means? Velyvet? Trick or treat? (.) Anybody 
Faisal No! What does it//

400

Tom //Well, it means, OK so they knock on the door, erm, and trick or treat

401 Faisal [O::h, ] means, erm, "give us something that we would like, right, a TREAT!",

402 Tom [and if,] "and if you DON'T, then we're gonna PLAY a TRICK

403

404

405

406

407

408

Ss $\quad$ [Ah] (laughter) on you, we're gonna DO something to YOU!"

Tom [You know like] we'll, you know maybe knock over your garbage

409 S Yes?// can or throw eggs at your window (jokey tone). Something! (laughs)

Tom // play kind of a TRICK on [you]

410

Faisal [OK, OK]

411

412 Faisal [Yeah (laughs)]

Tom

Right? So it's kind of like, it's kind of

413 Ss [(laugh)]

414 Tom "give us, give us, give us half of your erm, your income or we're

415 gonna burn your business down or break your legs!" (in aplayful voice)

416 Ss (laugh)

Since this particular Halloween was the first for Faisal, who had at that time just moved to Canada, Tom made a point of checking whether he was familiar with trick or treat. The easier concept of 'treat' was dispensed with by way of a swift explanation (line 400) but the notion of 'trick' obviously needed more elaboration with vivid examples from Tom such as knocking over one's garbage can or throwing eggs at one's window (line 406), paying protection money from the mafia (lines 410 to 411), giving half of one's income, burning a business down or breaking one's legs (lines 414 to 415). The humour lies not only in Tom's exaggerated examples but also the performative quality of his speech. His laughter, the tone and loudness of his voice and his non-verbal gestures give a playful quality to his utterance. These paralinguistic and discoursal signals work as interpretative cues to the students indicating 'time for play'. Clearly and this was made clear by Tom's use of humour, the practice of 'trick' in the usual Halloween tradition does not include paying protection money or breaking one's leg.

\section{Extract 2 Teasing means liking}

It was right after lunch and the class was to go on a field trip to a library nearby. They had to wait for one of the students, Elias, who was late. The teacher, Tom, teases Elias about his tardiness.

18 Tom we have it we have it on tape that you're late! (laughs) (points to researcher's audio recorder on the desk)

19 Ss (laugh)

20 Mabel I'm counting the number of times that you're late, Elias. (laughs)

21 Ss [(laugh)]

22 Mara [ September fifteen,] one o'clock, it's one- oh- two, Elias!

23 Ss (loud laughter)

24 Tom you are, [(laughs)] you are OFFICIALLY being TEASED (laughs)

25 Ss [(laugh)]

26 Tom how does it feel Elias, you're OFFICIALLY being TEASED. 


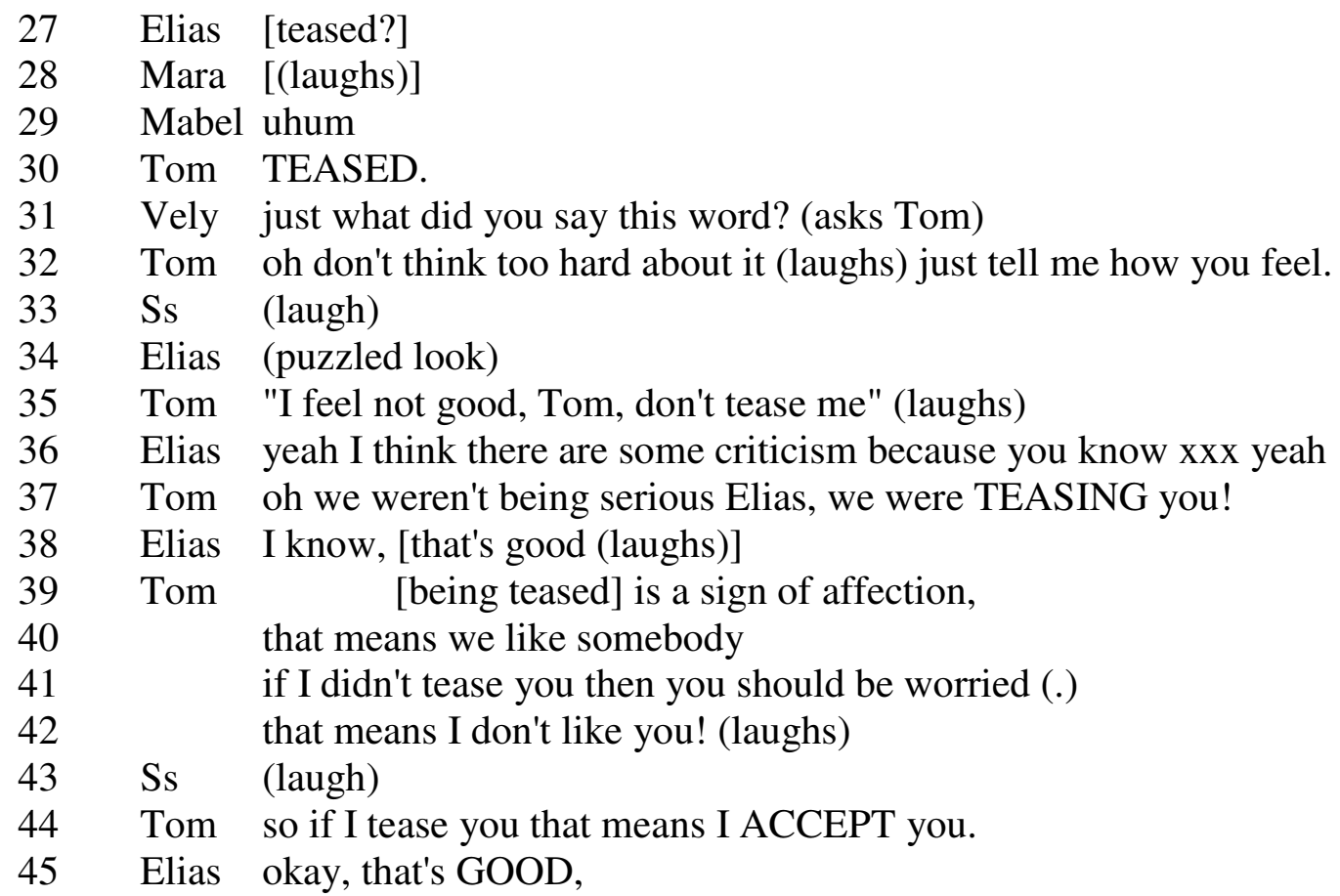

When Tom used the word 'teased' in lines 24, 26 and 30, there is no uptake from Elias which indicates that he did not know what the word meant. Another student, Vely (line 31) asks for clarification about the word. Tom then explains that teasing is a sign of affection (lines 39 to 42 ) and acceptance (line 44). What makes the above extract particularly relevant for language classrooms is the teacher's explicitness and willingness to explain what he was doing. It is probably his awareness that his students come from different sociocultural norms that makes him extra vigilant in preventing misunderstanding. On the other hand, it must be acknowledged that having to spend too much time explaining the meaning of a phrase or word can dilute or 'delete' humour and in fact, can be perceived as negative in some cultures.

Elias in line 37 ('I think there are some criticism...') alluded to the Janus-faced aspect of teasing which could be used to 'bite' or 'bond' (Boxer and Cortés-Conde 1997). While teasing can be used to appeal to rapport building, it has also been used to criticize, humiliate, bully, and control another person's behaviour. The biting effects of teasing could easily lead to conflict or misunderstanding and therefore must be deployed with great caution especially in culturally and linguistically diverse classrooms.

\section{Extract 3 Let your hair down}

On this particular morning, the mood was sombre and serious discussing the topic 'barriers to employment faced by immigrants in Canada'. Just before breaking for coffee, Tom addresses Phillip:

170 Tom we come back in (fifteen?) minutes? I'm gonna be talking a little bit about

171 erm (.) I erm I want you to DO some, some specific research for me on

on

172 information interviews (.) I put some topics up on the board

173 (points to the board) and erm erm a little bit of what I want you to do.

174 SO, (.) TIME to RELAX! 
The heart of the humour in the above extract is the use of irony. Tom capitalises on the fact that Phillip has a shaved head so letting his hair down cannot be taken literally. His emphatic use of 'time to relax' (line 174) immediately before 'let your hair down' (line 175) makes the meaning of the idiomatic expression explicit. Tom's appeal to playfulness seems to be that of releasing tension and relieving anxiety related to the previous sombre discussion of the numerous barriers that the immigrant students have to overcome to find a job in Canada. It is similar to the notion of 'fairground' or breaks in lectures (cf.Wang, 2012). The playful talk can also be interpreted as a face-mitigating device to soften Tom's directive (lines 171 to 173, telling students to do more research on information interviews after the break).

\section{Extract 4 Chicken and Egg}

The extract below was taken between a teacher-centred lecture and a writing task.

1 Tom first of all, let's do a CHICKEN and EGG thing here,

2 a chicken and egg thing! you guys erm

3 should we do a CHICKEN and EGG thing? (2.0) chicken and egg?

4 Elias yeah (smiley voice).

5 Ss (laugh)

6 Tom (smiles) yeah! yeah! (laughs) I'm just gonna say YU::P! (in a teasing voice)

7 Ss (laugh)

8 Tom o::kay, chicken and egg (3.0) what does that mean?

9 Elias chicken and egg, (in a smiley, teasing voice)//

10 Tom // chicken and egg,

11 Fai [which one is first]

12 Jinky [which came]

13 Fai which came first

14 Tom which is first! that's right! so we're gonna PRIORITISE,

Extract 4 shows Tom trying to check students' knowledge of 'chicken and egg'. The ensuing exchanges appear to be unplanned, the amused reactions largely due to the student's participation (lines 4 to 9). Elias's playfully ambiguous responses (lines 4 and 6) to Tom elicited the laughter. He did not seem to know what 'chicken and egg' meant so he resorted to humour as a face-saving device (Wang, 2014). Tom, having inferred the student's paralinguistic cues (non-verbal gestures) and prosody (smiley voice) as signifying an invitation to play (lines $6,8,10$ ), decided to go along with them. Then, Fai and Jinky (lines 11-3) gave the correct response 'which came first' to which Tom agrees and recasts the term to 'prioritise'.

\section{$\underline{\text { Discussion }}$}

The aim of this article has been to show how the off-task spaces of the classroom can be transformed into a vibrant teaching/learning space through the use of humour. In Extract 1 'trick or treat' the examples of 'trick' (protection by the mafia, burning your house down, etc.) given by the teacher performed the dual function of eliciting 
laughter and elaboration (Deroey and Taverniers 2011). The students receive information about how a specific cultural practice is observed in the host country. In other words, off-task was in actuality right on-task.

Extract 2 explored a spontaneous teaching 'moment' that became a lesson in vocabulary and pragmatic skills. The dictionary definition of teasing normally refers to it as poking fun at someone to criticise, hurt their feelings or provoke a certain reaction. The teacher's explanation of teasing as 'liking' and 'acceptance' gave the students another possible interpretation of the meaning of the word, as used in reallife settings. The teacher's expression of affection arguably contributed to establishing a bond between teacher and student in this specific context, although it might well backfire in other contexts if teasing were to lead to embarrassment.

Extract 3 centred around the idiomatic expression 'let your hair down'which might well present problems to L2 learners. However, the teacher strategically used 'time to relax' (line 173) before 'let your hair down' so that the meaning was clearly contextualised. Singling out Phillip, with his shaved head, the teacher let the class know that the expression was not to do with hair but with relaxing. The laughter at the end of the exchange indicated that the utterance was interpreted as being amusing by at least some of the students.

Extract 4 showed how the transition space between activities is able to open up a spontaneous opportunity for teacher and students to share a laugh and at the same time elicit understanding of a specific idiomatic phrase, in this case 'chicken and egg'. The humourous element was unplanned and a result of the teacher and student's coordinated actions instead of being solely initiated by the teacher.

The extracts analysed here are illustrative examples of how the teacher in this particular class often used humour in the off-task spaces of the classroom. This is not to say that he did not use humour during the lessons but it was my intention to shine the spotlight on obscure spaces and explore how they can be mined for opportunities to teach new vocabulary, pragmatic skills and sociocultural knowledge. The immigrant students were taught the concept of 'trick or treat' as part of the Canadian sociocultural practice of Halloween; they observed how 'letting one's hair down' in the context of taking a break and relaxing; and for some students, their knowledge of the metaphoric adjective 'chicken and egg' was reinforced. In addition, the students witnessed 'teasing' in action instead of just knowing its dictionary definition. Through their playful interactions with the teacher, I suggest that they gained some insights into the Canadian adult education classroom. Indeed, people from different cultures have their own pre-conceived notions about teacher-student relationships. Many of them might be familiar with the traditional I-R-F (initiation-response-follow up/feedback) classroom structure and the notion of the teacher as an authority figure. Arguably, the potential for miscommunication is heightened when there is a lack of shared educational norms. Yet, getting the students accustomed to a certain 'play space' at predictable phases of the day's lesson would make the contextualization cue of 'let's play' less likely to be misinterpreted. It would also save the teacher from having to make decisions as to when to cut-off humorous talk to get back on track. Indeed, Waring (2013: 207) notes that there are associated dilemmas with playful talk in the classroom such as 'how teachers can regain control when play imposes a subversive order in the classroom or what teachers' decision-making processes are regarding when to permit or cut off play'. Deploying humour in off-task spaces makes these quandaries less of a concern because of 'natural built-in boundaries' between on-task or curriculum-oriented spaces and the 'less legitimate' interstices. 
The institutional nature of classroom talk tends to favour the transactional use of language to instantiate the 'serious' aspect of learning. However, L2 learners need opportunities to at least notice, if not practise, how language can be used to establish friendly relations (Victoria, 2014). Unofficial spaces make the enjoyment of sociality and playful talk allowable. Teasing or funny comments which might be perceived as inappropriate or disruptive within the official curriculum space can be mined for their utility within the play space.

\section{Conclusions}

The four illustrative extracts show how teachers could use off-task spaces such as those while they are getting the audio visual equipment to boot up, whilst waiting for the rest of the students to arrive, just before a coffee or tea break, and during transition moments between activities into a pedagogical resource through humour The limitations of this paper are self-evident. The transcribed audio data that was analysed can only partially represent the complexities of classroom reality. Although I was present as participant observer, my focus tended to be on 'speaking' interactants whose facial reactions and non-verbal gestures I could see. And indeed, despite the observable smiles and laughter, I cannot claim with certainty that those students found the teacher's utterances to be amusing or if they had understood the playful intent at all. Additionally, I have not provided solid evidence that humour has resulted in actual learning, only that teaching attempts have taken place. I have stated however, that there are many factors that work in tandem for learning to happen. To attribute direct causality between humour and learning would require further investigation. Also the results reported here might not be applicable in some contexts. Arguably, as one reviewer points out, class size and composition, the students' level of proficiency, age, and motivation to learn English all have a bearing on how humour is enacted. Furthermore, findings from an ESL environment in Canada might not apply to EFL settings owing to the different affordances and proximity to target language that ESL contexts provide (Waring, 2013).

Nevertheless, while the study is limited in scope, it directs our attention to those often overlooked and undervalued non-curriculum oriented spaces waiting to be explored for their potential in providing affordances and opportunities for relationship building between teachers and students. It could take as little as few minutes before and after the lesson or in-between reading and writing activities. In the first place, 'all work and no play...'

\section{$\underline{\text { References }}$}

Bell, N. D. (2006). Interactional adjustments in humorous intercultural communication. Intercultural Pragmatics, 3(1), 1-28.

http://doi.org/10.1515/IP.2006.001

Bell, N. D. (2009). Responses to failed humor. Journal of Pragmatics, 41(9), 18251836. http://doi.org/10.1016/j.pragma.2008.10.010

Boxer, D. \& F.Cortés-Conde. (1997). From bonding to biting : Conversational joking and identity display. Journal of Pragmatics, 27, 275-294. http://doi.org/10.1016/S0378-2166(96)00031-8

Deroey, K. L. B., \& M. Taverniers. (2011). A corpus-based study of lecture functions. Moderna Sprak, 105(2), 1-22. 
Downs, V. C., M. M, Javidi, \& J.F. Nussbaum. (1988). An analysis of teachers' verbal communication within the college classroom: Use of humor, self-disclosure, and narratives. Communication Education, 37(2), 127-141.

Garner, R. L. (2006). Humor in pedagogy: how ha ha can lead to aha! College Teaching, 54(1), 177-180. http://doi.org/10.3200/CTCH.54.1.177-180

Holmes, J. (2000). Politeness, Power and Provication: How Humour Functions in the Workplace. Discourse Studies, 2(2), 159-185.

Victoria, M. P. (2014). English: its role as the language of comity in an employment programme for Canadian immigrants. Globalisation, Societies and Education, (November), 1-21. http://doi.org/10.1080/14767724.2014.937401

Wang, Y. (2012). Chinese Students' Perceptions of Humour in British Academic Lectures. The Open University.

Wang, Y. (2014). Humor in British academic lectures and Chinese students' perceptions of it. Journal of Pragmatics, 68, 80-93.

http://doi.org/10.1016/j.pragma.2014.05.003

Waring, H. Z. (2013). Doing being playful in the second language classroom. Applied Linguistics, 34(2), 191-210. http://doi.org/10.1093/applin/ams047

White, G. W. (2001). Teachers' report of how they use humour with students perceived use of such humour. Education, 122(2), 337-347.

Ziyaeemehr, A., V. Kumar, \& M. S. F Abdullah. (2011). Use and non-use of humour in academic ESL classroms. English Language Teaching, 4(3), 111-119.

\section{The author}

Include here brief bio-data (maximum 75 words). Start off with your name in bold and if you wish, include at the end your email address as follows.

Mabel Victoria was involved in language teaching and teacher education in the United Kingdom for many years before moving to New Zealand. She has published mainly in the areas of language teaching methodology and language learning. She is now working in the Language Centre at the University of XXX

Email: M.Victoria@napier.ac.uk

\section{Appendix: Transcription Conventions}

\begin{tabular}{|c|c|}
\hline (.) & a brief pause \\
\hline & falling intonation at end of tone unit \\
\hline$?$ & high rising intonation at end of tone unit \\
\hline & slightly rising intonation at end of tone unit \\
\hline & animated intonation \\
\hline & unfinished utterance, e.g., false start, self-correction \\
\hline $\begin{array}{l}\text { WORD } \\
:\end{array}$ & $\begin{array}{l}\text { Words written in capitals to indicate emphatic stress: e.g. VERY } \\
\text { noticeable lengthening of a vowel }\end{array}$ \\
\hline [words] & A: $\quad$ o::h, I'm sorry. \\
\hline [words] & $\begin{array}{l}\text { simultaneous speech indicated in brackets: e.g. } \\
\text { A: } \mathrm{mm} / / \text { Did you [read the report] } \\
\text { B: } \quad \text { [didn't have the] time }\end{array}$ \\
\hline
\end{tabular}


// latching, no perceptible pause after a turn

A: I'm going to be late //

B // me too

(laughs) description of current action, transcriber's comments

Ss refers to unidentified multiple speakers 